\|Volume 9, Issue 6, June 2020\|

\title{
Mitigation of Harmonics by Using Shunt Hybrid Active Power Filter in 3-Phase 4-Wire System
}

\author{
Gumalapuram Gopal ${ }^{1}$, B.Narsimha Reddy ${ }^{2}$ \\ Assistant Professor, Dept. of EEE, Mahatma Gandhi Institute of Technology, Hyderabad, Telangana, India ${ }^{1}$ \\ Assistant Professor, Dept. of EEE, Mahatma Gandhi Institute of Technology, Hyderabad, Telangana, India ${ }^{2}$
}

\begin{abstract}
The various non-linear loads in electrical distribution system produce harmonics. These harmonics degrade the power quality in voltage and currents. The researchers suggested different techniques to mitigate these harmonics. In these developments, Passive Power Filter \& Active Power Filters (APF) is used individually for several improvements in power quality. The researchers had explained that, in high power applications, the cost of active power filter is increased and also increased the switching losses. In this paper, the hybrid combination of passive and active power filter i.e. Shunt Hybrid Active Power Filter (SHAPF) has been developed to eliminate current harmonics caused by nonlinear loads in 3-phase 4-wire system. In the proposed system, to generate the required reference current, the D-Q Synchronous Reference Frame (SRF) current control method is used. The proposed system developed in MATLAB/SIMULINK environment for unbalanced source condition and the results are shown at the end.
\end{abstract}

KEYWORDS: Passive Power Filter, Active Power Filter, Shunt Hybrid Active Power Filter

\section{INTRODUCTION}

The study of power quality is necessary at present electrical system. The main reason behind power quality degradation is an increase usage of power electronic devices for power conversion and speed control of drives. Now days, the most of the modern loads are nonlinear which generates harmonics and leads to the distortion of voltage and current from the fundamental waveforms [1-2]. The power companies and their customers at distributed centers equipped with sensitive devices may have power outages for a short period of time that will lead to a large amount of loss. The study of power quality disturbance detection is must to reduce the occurrence of outage, and to improve the quality of electrical power [3].

Passive filters can be a solution for mitigation of harmonics, but the major drawbacks including fixed compensation, bulky devices and the resonance problem of the L-C filters. Next, Active Power Filter (APF) has been developed for effective compensation of harmonics. They have the ability of compensate the harmonics and also have the quality to convert the unbalanced load to a balanced [4-5]. The main drawbacks of APF's like high in cost and rating constraints by powerdevices.

Shunt Hybrid filter topology has been chosen which is a combination of a parallel-connected passive filter and a small rated active filter. This configuration has been considered in this paper for its effective operation. There are so many control schemes to accomplish the desired results. But among them SRF (Synchronous Reference Frame) is one of the most conventional and practically applicable methods. For doing the synchronization SRF requires a PLL circuit. Though the performance of conventional PLL is low, that's why a control scheme of Synchronous Reference Frame method with the modified PLL has been represented in the paper [6].

\section{IMPLEMENTATION OF SHUNT HYBRID ACTIVE POWER FILTER TOPOLOGY}

The order of frequency that needs to be filtered decides the power rating of active power filter. So, active power filter is employed to decrease lower order harmonics with lower power rating which in turn reduces size and cost of it. Figure 1 depicts the general block diagram of SHAPF consisting of both shunt active filter and passive filter. 
||Volume 9, Issue 6, June 2020\|

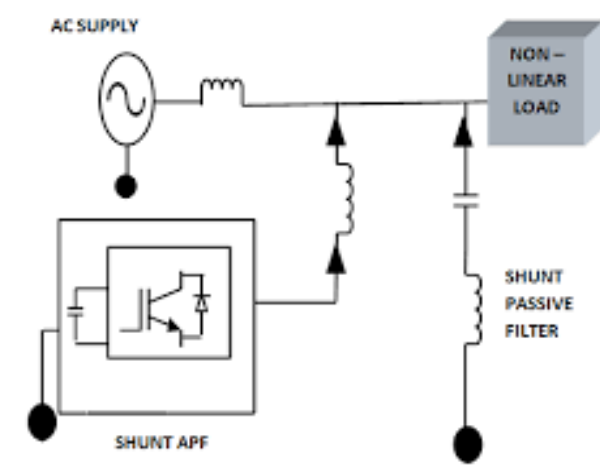

Fig.1. Block diagram of Shunt Hybrid Active Power Filter

In 3-phase system, the APF works with a combination of 3-leg inverter with two splittedcapacitor with the combination of 1-phase and 3-phase loads in a parallel connection that has been considered as a non-linear and unbalanced load for a 3-phase 4-wire distribution system. Through an inductor the inner point of every branch is connected to the power network which will help to filter the ripples of inverter current. At the $5^{\text {th }}$ harmonic tuned frequency, the LC passive filter is connected in shunt to the power line before the load. This provides a low impedance trap for harmonics to which the filter is tuned.

\section{CONTROL ALGORITHM FOR PROPOSED SYSTEM}

In the proposed case, the modified phase-locked loop, generation of reference current \& DC link capacitor voltage control are covered.

\section{A. PHASE-LOCKED LOOP (PLL)}

In this study, the modified PLL helps us to determine of positive sequence components with stability and rapidity shown in Fig.2.

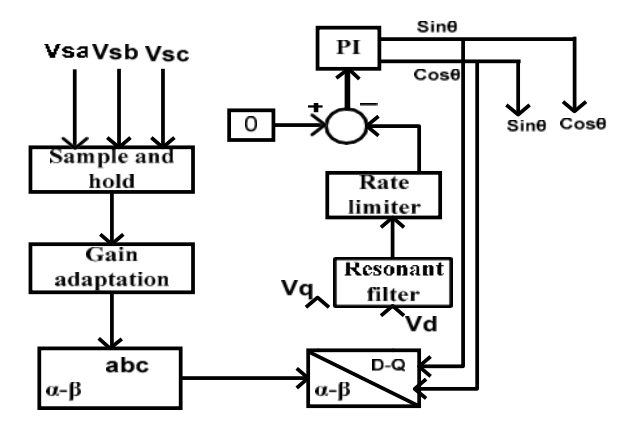

Fig.2 Block diagram of Phase-Locked Loop

\section{B. REFERENCE CURRENT GENERATION}

In the 3-phase system, load currents have been measured by using hall-effect current sensor and converted into dq-0 by means $\mathrm{I}_{\mathrm{La}}, \mathrm{I}_{\mathrm{Lb}} \& \mathrm{I}_{\mathrm{Lc}}$. The load currents id and iq are calculated and they are allowed to pass over a low pass filter to separate the AC and DC part. By separating these parts the active and reactive fundamental current components (id$\mathrm{DC}$, iq-AC) are obtained. In order to generate the accurate references to the modulator, the filtered active and nonactive currents are used.

\section{DC LINK CAPACITOR VOLTAGE CONTROL}

The control loop of DC voltage through PI controller is very effective. To control inverter current actively the nominal DC bus voltage $V_{d c}$ should be selected as $V_{s}<V_{d c} \leq 2 V$. The capacitor voltage can be chosen from the below equation 
||Volume 9, Issue 6, June 2020\|

$$
C_{d c}=\frac{\pi I f}{\sqrt{3 . . \omega \cdot V_{d c(p-p) \max }}}
$$

\section{SIMULATION DIAGRAM \& RESULTS}

By using MATLAB/Simulink, a 3-phase 4-wire power system network with shunt active and shunt passive filter are developed as shown in Fig.3 and internal configuration of SHAPF is shown in Fig.4.

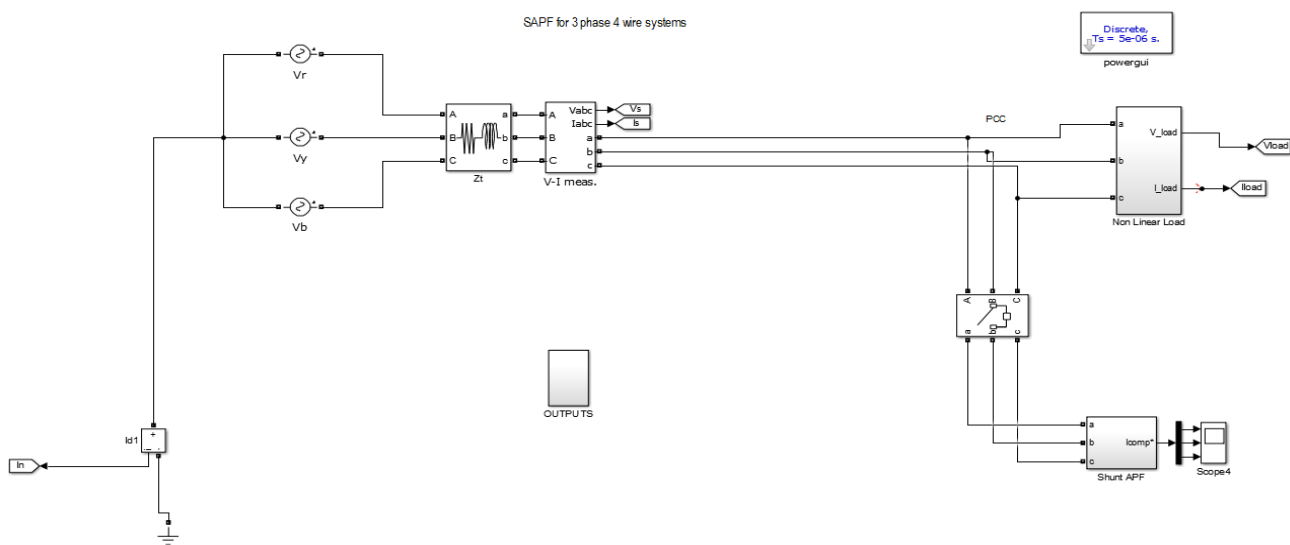

Fig.3.Simulation diagram for 3-phase 4-wire system with Shunt Hybrid Active Power Filter

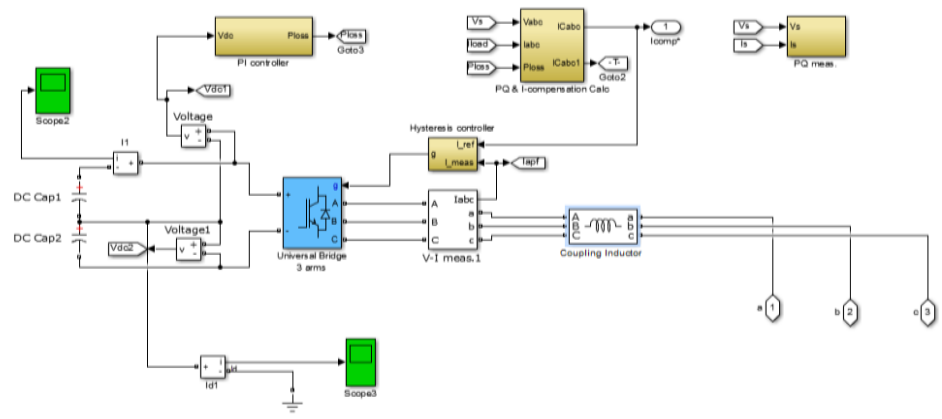

Fig.4.Internal diagram of Shunt Hybrid Active Power Filter

The simulation results are obtained for unbalanced source voltage conditions in the time period from 4.9 to $5 \mathrm{sec}$ are shown in Fig.5 to Fig.12. For the unbalanced source Fig.5 represents the unbalanced source voltages. Fig.6 shows the load current which is non-linear in nature. Total Harmonic Distortion (THD) has been shown by using FFT analysis in Fig.7. The passive filter connected in the circuit, and then the load current has started to become linear in nature which is represented in Fig.8 as well as the THD also shown in Fig.9. The load current after insertion of the SHAPF total compensation with PI controller is shown in Fig.10. The FFT analysis after connecting SHAPF has been shown in Fig. 11 which represents the appropriate THD, below 5\% as per IEEE-519 standard. The source voltage became fully balanced after connecting SHAPF and it is shown in Fig.12. 
||Volume 9, Issue 6, June 2020\|

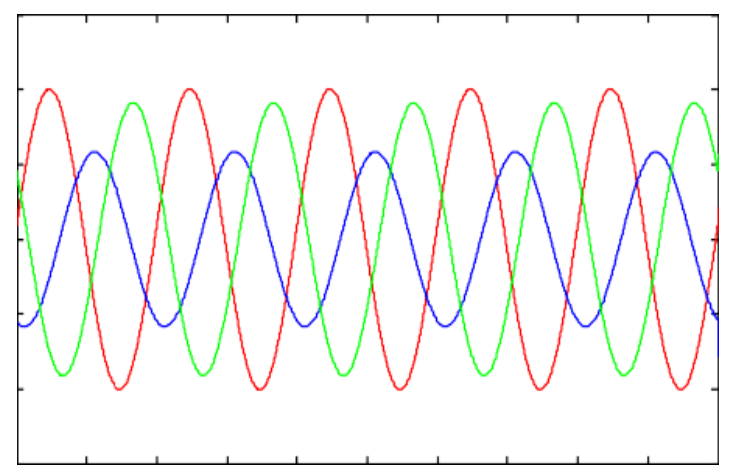

Fig.5. Unbalanced Source Voltages

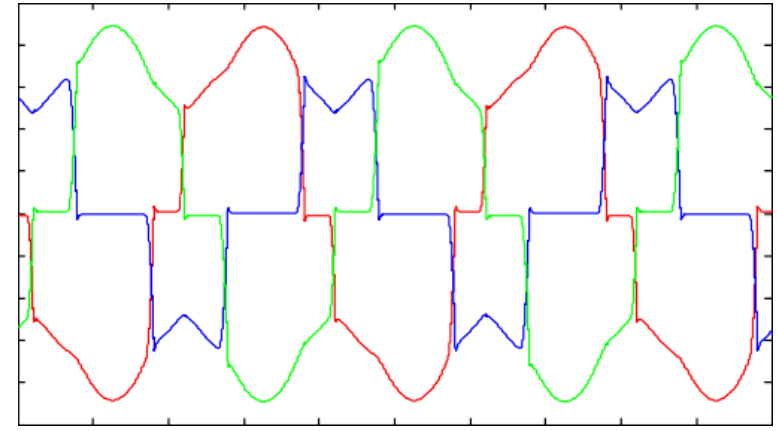

Fig.6.Load current without passive filter

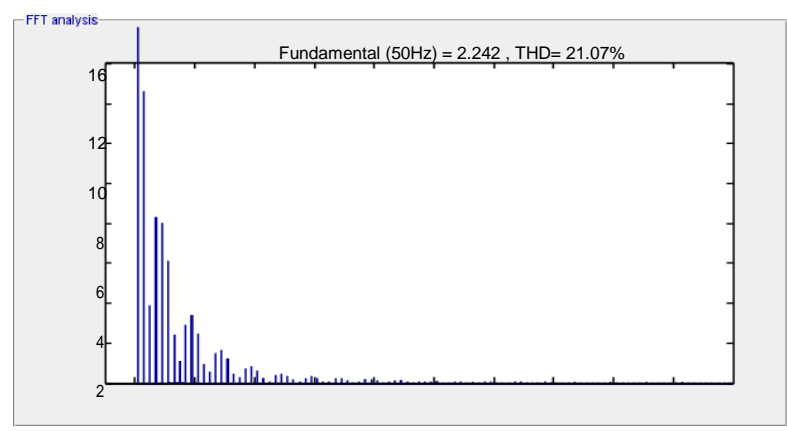

Fig.7.Total harmonic distortion without passive filter

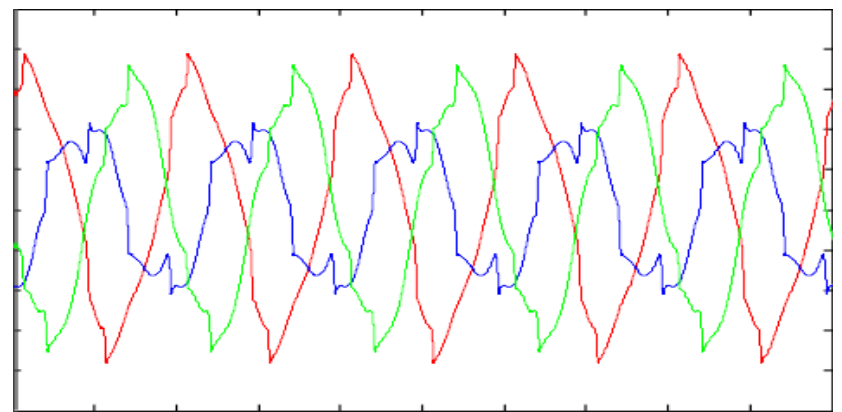

Fig.8.Load current with passive filter 
||Volume 9, Issue 6, June 2020\|

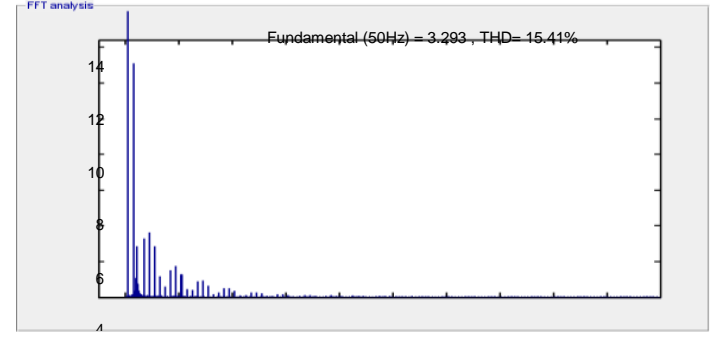

Fig.9.Total harmonic distortion reduced to $15.41 \%$ with passive filter

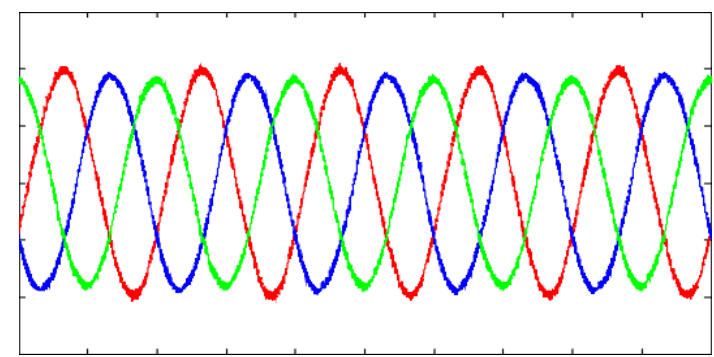

Fig.10.Load current with SHAPF

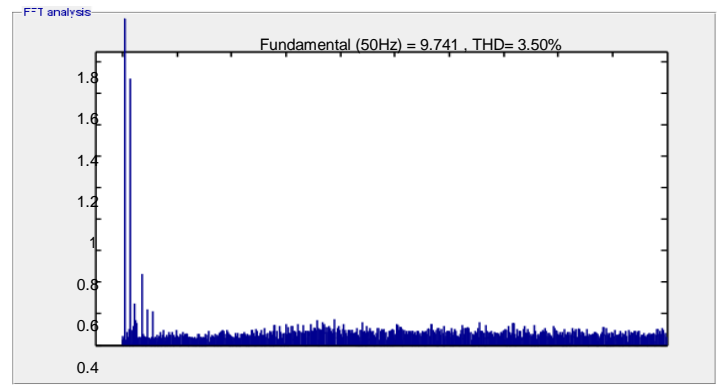

Fig.11.Total harmonic distortion reduced to $3.5 \%$ with SHAPF

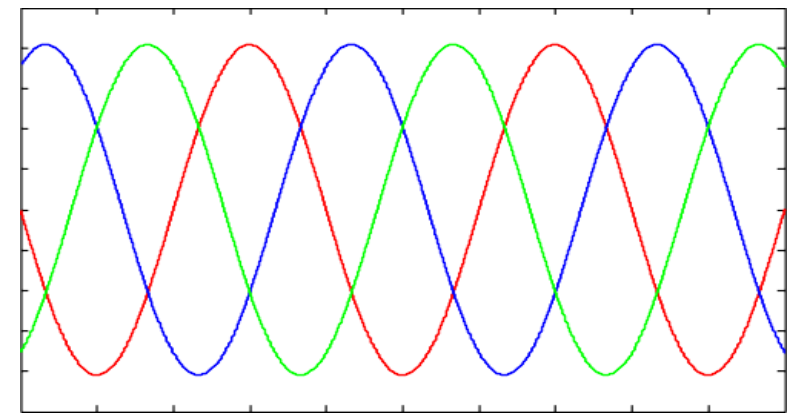

Fig.12. Balanced source voltages after compensation by SHAPF

\section{CONCLUSION}

The control technique for shunt hybrid active power filter (SHAPF) has been implemented successfully. In order to grid voltage synchronization under unbalanced conditions, the modified PLL is discussed and used in the proposed system. For the above case, the load current is linear and THD has been reduced to $3.50 \%$. Therefore, SHAPF can be considered as an effective harmonic mitigation method for filtering. 


\section{||Volume 9, Issue 6, June 2020\|}

\section{REFERENCES}

[1] Xiaodong Liang, "Emerging power quality challenges due to integration of renewable energy sourses,"in IEEE Industry Applications Society Annual Meeting, 2016, pp. 1-9.

[2] Akagi H, Srianthumrong S and Tamai Y 2003 Comparisons in circuit configuration and filtering performance between hybrid and pure shunt active filters. Proc. Conf. Rec. IAS Annual Meeting 2: 1195-1202.

[3] P.Kanirajan, V.Suresh Kumar, "Power quality disturbance detection and classification using wavelet and RBFNN", Applied Soft Computing, Volume 35, October 2015, Pages 470-481.

[4] S. S. Patnaik and A. K. Panda, "Real-time performance analysis and comparison of various control schemes for particle swarm optimization-based shunt active power filters," International Journal of Electrical Power \& Energy Systems, vol. 52 pp. 185-197,2013.

[5] A. Nasiri, A. E. Amac, and A. Emadi, "Series-Parallel Active Filter/Uninterruptible Power Supply System," Electric Power Components and Systems, vol.32, pp. 1151-1163,2004.

[6] R. Tahmid and S. Ahmad, "Power quality improvement by using shunt hybrid active power filter," 2017 International Conference on Electrical, Computer and Communication Engineering (ECCE), Cox's Bazar, 2017, pp. 381-386, doi: 10.1109/ECACE.2017.7912934.

[7] P. Dey and S. Mekhilef, "Synchronous reference frame based control technique for shunt hybrid active power filter under non ideal voltage," 2014 IEEE Innovative Smart Grid Technologies Asia (ISGTASIA), KualaLumpur, 2014,pp.481-486.

[8] P. Salmeron and S. P. Litran, "A control strategy for hybrid power filter to compensate four wires three-phase systems," IEEE Transactions on Power Electronics, vol.25,pp.1923-193,2010. 